Cite as: Shonfeld, M., \& Kritz. M. (2013). Virtual representations in 3D learning environments. Interdisciplinary Journal of E-Learning and Learning Objects, 9, 249-266. Retrieved from http://www.ijello.org/Volume9/IJELLOv9p249266Shonfeld0863.pdf

\title{
Virtual Representations in 3D Learning Environments
}

\author{
Miri Shonfeld and Miki Kritz \\ Kibbutzim College of Education Technology \& Arts, \\ Tel Aviv, Israel
}

\author{
Mirisho@smkb.ac.il miki kri@smkb.ac.il
}

\begin{abstract}
This research explores the extent to which virtual worlds can serve as online collaborative learning environments for students by increasing social presence and engagement. 3D environments enable learning, which simulates face-to-face encounters while retaining the advantages of online learning. Students in Education departments created avatars that represented them at collaborative meetings and activities. The study examines students' choice of Avatar appearance in relation to their own appearance and their prevailing social and cultural norms. It compares the appearance of avatars chosen by students from different countries and cultures through analysis of observations, questionnaires, and interviews. Does the user's appearance affect his/her avatar's appearance? Does the user's culture affect his/her choice of avatar? Do 3D environments blur multicultural differences? Do similarities between students and their avatars contribute to their learning experience, and if so, in what way? Results indicate that although virtual 3D environments provide freedom, external contexts create powerful boundaries and expectations, leading many participants to seek a socially acceptable online appearance influenced by their cultural norms, as well as by online group identity. This study extends the dual-congruity perspectives of the Avatar Choice Model to a conceptual framework based on a quad-congruity perspective, including the importance of the online group and adding the constraining effect of offline culture and norms on virtual representations.
\end{abstract}

Keywords: Avatars, virtual worlds, 3D learning environments, online multicultural differences, Avatar Choice Model

\section{Introduction}

Material published as part of this publication, either on-line or in print, is copyrighted by the Informing Science Institute. Permission to make digital or paper copy of part or all of these works for personal or classroom use is granted without fee provided that the copies are not made or distributed for profit or commercial advantage AND that copies 1) bear this notice in full and 2) give the full citation on the first page. It is permissible to abstract these works so long as credit is given. To copy in all other cases or to republish or to post on a server or to redistribute to lists requires specific permission and payment of a fee. Contact Publisher@InformingScience.org to request redistribution permission.
As broadband Internet access and virtual reality technology rapidly expand, virtual worlds and three-dimensional avatars are being widely adopted (Suh, Kim, \& Suh, 2011). Therefore, during their studies, pre-service teachers are exposed to virtual teaching environments that are becoming part of our world (Campbell, 2009). In these environments, students gain their identity through avatars, which can be reshaped. 
Avatars enhance social presence, engagement in learning, and interactions with other students (Resta \& Shonfeld, 2013). Furthermore, this study shows that virtual representations, which highly resemble the students and reflect their culture, strengthen students' ability to assimilate into a group, collaborate with its members and perform cooperative tasks, and contribute to the learning experience.

Realizing the need to prepare pre-service teachers for advanced teaching environments, undergraduate students from seven teacher training colleges in Israel (two Jewish secular colleges, two Jewish religious colleges, two Arab colleges, and one mixed public college) studied in various online environments including three-dimensional (3D) environments according to the TEC model (Shonfeld, Hoter, \& Ganayem, 2013). This was only a unit in the central point of a one year online collaborative course that was aimed to expose students to study in a multicultural environment. The virtual worlds served as a platform to meet visually and by oral communication while there was a possibility to hide the real appearance through Avatars (Hoter, Shonfeld, \& Ganayem, 2009).

Graduate students from the Kibbutzim College and Texas University also met in these environments while participating in joint courses (Resta \& Shonfeld, 2013). They were trained to use 3D virtual environments such as Second Life $(S L)$. They collaborated in groups, creating educational activities such as role-playing or touring and exploring different countries, museums and archeological sites (e.g., http://www.youtube.com/watch? $\mathrm{v}=\mathrm{Tb} 17 \mathrm{~m} 2 \mathrm{gJ} 7 \mathrm{zo} \&$ feature=youtu.be). In this experience, the whole collaborative project took place in Second life. They were requested to design a learning activity that uses the affordance of a $3 \mathrm{D}$ virtual environment. They met their partners from the different countries through virtual worlds and were exposed to the potential benefits and limitations of virtual worlds to support collaborative learning. Similar educational activities were also used by other groups of undergraduate students from Israel and collaborative universities from Texas, Denver, and Arizona to study culture, and by groups of undergraduate students from different countries to study language. These undergraduate and graduate groups of students were the subjects of a study that investigated virtual representations and their contribution to learning (Shonfeld \& Raz, 2012).

The study observed how students chose their virtual representations and compared it with existing models that explain this process. According to Suh, Kim and Suh (2011), the more the avatar resembles its user (self-congruity), the more likely the user is to have a positive attitude toward his avatar. Yet, the user will also choose or shape her or his avatar according to its purpose (functional congruity) - thus they propose the dual-congruity perspectives model. Other researchers found a third element relating to the identity of the virtual group (or environment) in which the avatar is being used (group-congruity) (Martey \& Consalvo 2011). This research examined these three elements of the Choosing Avatar Model found in the literature and proposes a fourth perspective. In addition to self-congruity (physical similarity of the user to her or his avatar, e.g., skin or hair color, weight, etc.), we assume that a cultural congruity will be found, expressing itself in the avatar's style of dress. That is, religious or conservative users will prefer a conservatively dressed avatar (e.g., preferring a dress over trousers or a long dress over a short one). Thus, by adding the importance of the constraining effect of offline culture and norms, this study describes a quad-congruity perspectives model, which describes the four factors involved in choosing avatars and explains users' attitudes toward their virtual representations in realistic, taskfocused virtual world settings.

This research also examined students' opinions regarding the contribution of this model to their learning experience. The assumption was that a high-level of congruency between students and their avatars (self, functional, group, and cultural) will make the student feel better in the virtual group, enabling better assimilation and collaboration with other members to accomplish tasks and 
will thus contribute to the learning experience. Such a contribution may enrich diverse new learning possibilities.

This paper describes the theoretical background of virtual environments, of avatars, and of using avatars for learning. Choosing and shaping an avatar is an important factor in the relationships between users and their avatars, so we will describe the existing models for choosing avatars. The paper will present findings, showing differences in the appearance of avatars in different groups, implying the existence of cultural differences in choosing avatars. This paper will focus on the implications of these findings, especially on the apparent contribution of "culturally-customized" avatars to the learning experience of the students, and the contribution of the virtual learning environment to learning, according to the students' opinions. Finally, the discussion and conclusions of these findings will point out the limits of this study and suggest a direction for further research.

3D learning environments such as Second Life (SL) are being used in growing numbers. Kibbutzim College, like many other academic institutions, invested resources in that area, including the purchase of an island in $S L$, upon which the virtual Kibbutzim College was constructed. Such an investment requires research, evaluation, and supervision of the various components of these environments in order to evaluate their effectiveness on teaching. This study hopes to promote the understanding of some of the factors that encourage learning in $3 \mathrm{D}$ environments, to contribute to the improvement of educational products, and to encourage further research in this field, in the framework of teacher education.

\section{Literature Review}

\section{Avatars and Virtual Environments}

An avatar is an electronic image that represents and is manipulated by a computer user like in a computer game ("Avatar," n.d.). In 3D learning environments, students are represented by avatars, which enable them to meet, interact, and collaborate. Participants can select ready-made avatars in various shapes and forms or create custom-made ones. In many of these environments, it is possible to reshape and design the virtual representations according the rules and possibilities of the underlying software.

Many types of virtual environments have been created since the late 1990s. Some of them were less active and disappeared due to technological difficulties and high operating costs. Some of the most common of them are ActiveWorlds (http://www.activeworlds.com), BlueMars (http://bluemars.com), CloudPartyTime (http://www.cloudpartytime.com) and Moove (http://moove.com). Two-dimensional virtual environments such as WhyVille (http://www.whyville.net) and SimSchool (http://www.simschool.org) are more common in the field of education.

One of the most popular three-dimensional virtual worlds, which serves as a platform for multiuser activities and learning environments, is Second Life (SL), created in 2003. Its users ('residents') create and customize avatars in order to move around, interact, and communicate with one another in various settings. Through their avatars, users manipulate realistic-like objects in various ways. Unlike computer games, where players are challenged by obstacles and problems they have to solve so they can progress to the next level, $S L$ simulates reality. The main purpose is to create social connections with other people (avatars) and to accumulate property and capital. $S L$ allows residents to design and program objects, clothing, movements, and structures, resulting in vast possible environments and people. Basic avatar creation options allow minute adjustments to the shape, colors, textures, and sizes of every body part. A marketplace of user-created clothing 
and avatar shapes allows residents to purchase items that transform default appearances into a wide range of looks.

To participate in $S L$ one has to create a user account on its site, to download the free software, and to activate it with a username and a password. By the beginning of 2011, SL had about 18 million unique accounts with over one million active users and more than 1.85 billion square miles of user-developed land. Once logged in, the avatar begins to function in these areas according to the user's will, interests, and the situation. This virtual area, where people from all parts of the world meet, enables users to create, share, and experience almost any kind of element of the physical world, ranging from marketing, selling and consuming, studying and going out, to making social and romantic connections. The economic businesslike activities use virtual currency called Linden Dollar, which can be converted into real dollars. Advanced players in $S L$ create complete cities like Paris and London, buy land and build houses, hotels, clubs, roads, shopping centers, and institutions such as universities, colleges, museums, and public libraries. Lacking concrete risks in this world, there is no limit to creativity, which is the name of the game.

$S L$ 's many islands encompass a range of communities. In many, residents design sim environments (like cities in comics) and establish appearance norms that evoke a specific culture. Many of the more elaborate communities in $S L$ are role-playing areas, where residents adopt a certain appearance and speak in character as part of the stories they build together. Communities also form across sims, based on common features, such as furries and quads, who are identified by their part-human, part-animal appearance.

There are complex tools to design avatars. Even unskilled new players can choose many types of readymade dressed avatars and then change their shapes and the colors of skin and hair. Yet most avatars in $S L$ are human, young and beautiful Caucasians, corresponding to traditional gender distinctions in shape and dress. The freedom afforded by the interface is dramatically constrained by the social and cultural norms of appearance in this online world and, as we propose, also by the offline cultural norms of users, especially new ones (the more they fit into $S L$ subcultures and groups, the more these norms will prevail in the offline groups). To understand why people choose to appear as they do in the virtual world requires examining not only the expression and emergence of individual identities both online and offline, but also the broader social contexts in which they interact, again both online and offline (Abram, 2007; Boulos, Hetherington, \& Wheeler, 2007; Carmi \& Man, 2012; Jennings \& Collins, 2007; Martey \& Consalvo, 2011).

\section{Learning through Avatars}

There seem to be advantages for learning by using virtual environments and interactive avatars in supporting students' achievement and learning goals within conventional educational contexts, ranging from enhanced engagement in learning activities, to more purposeful and focused communication, and better cooperation and collaboration between students when used in groups (Falloon, 2010; Hamilton \& Nowak, 2010; Resta \& Shonfeld, 2013). Shonfeld, Resta, and Yaniv (2011) refer to enhancing engagement and social presence by using $S L$ environments. Other researchers extend these studies and explore the potential of avatar environments to act as powerful communication media for students to display knowledge and understanding and to engage in the development of higher order thinking skills, such as interpreting, analyzing, evaluating, synthesizing, and solving complex problems (Falloon, 2010).

The manner in which users in a synchronous shared environment are represented affects their ability to communicate. Therefore, the design of an avatar affects the communicative possibilities within a virtual world. The visual affects the verbal when both are mediated by technology (Kolko, 1999). That is, people are prone to develop deeper relationships with entities that have greater social potential (Hamilton \& Nowak, 2010). An avatar's appearance influences the development of thought. Its dressing style leads the students' course of thought accordingly. The 
opment of thought. Its dressing style leads the students' course of thought accordingly. The look of a professor will inspire an atmosphere of learning and will lead to a pedagogic or scholastic course of thinking and writing, whereas a glamorous figure magnificently dressed will arouse thinking about entertainment, brands, etc. (Peña, McGlone, \& Sanchez, 2012). In other words, when designing learning in a virtual world, we should consider the effect of the atmosphere inspired by the virtual characters which appear in it.

Many educational institutes conduct learning in virtual worlds. Libraries in $S L$ offer information resources and can encourage learning. Virtual libraries contain not only electronic books but also a variety of digital learning tools such as virtual labs, computer simulations, and interactive multimedia software which can enhance learning and the understanding of processes via dynamic and self-experienced learning (Carmi, 2008). Carmi and Man (2012) note that libraries try to remain relevant and updated by entering the $S L$ world which is grasped as the world of tomorrow. They can counsel and offer information about $S L$ through virtual tours and links to various libraries, collections, and databases in $S L$. As a simulation of the real world, $S L$ can be used for study tours in museums and historical and archeological sites as demonstrated in learning activities produced by students in this research, as exemplified in the introduction. Because they are computerized, $S L$ environments enable learning by constructing knowledge via self-experience and real interaction with the world. The investigation of learning in virtual worlds has just begun. Their learning potential highlights the importance of exposing pre-service teachers to these environments and the importance of research and evaluation of developing instruction in the near future (Campbell, 2009).

\section{Models of Choosing and Shaping Avatars}

Avatars are often interpreted as symbolic messages about the people they represent and have been found to increase the perceived social potential of an online partner (Bailenson, Swinth, \& Hoyt, 2005; Barret, 1997; Breazeal, 2003; Nass \& Moon, 2000; Reeves \& Nass, 1996). As an indication of intelligence and warmth, social potential can, in turn, influence communication outcomes, including attention and learning (DiSalvo \& Gemperle, 2003; Galanxhi \& Nah, 2007).

As viewers appraise potential avatars, they evaluate the extent to which the image communicates intellect, social competence, honesty, and reliability. Viewers wish to know if their image tells them that the entity the avatar represents is credible (Hamilton \& Nowak, 2010). Anthropomorphic intensity and realism (or believability) enhances the credibility of an avatar (Brahnam, 2009). More credible avatars are more likely to be selected for future interactions (Garau, Slater, \& Vinayagamoorthy, 2003; Nowak, Hamilton, \& Hammond, 2009; Nowak \& Rauh, 2008; Taylor, 2002; Yee \& Bailenson, 2007).

This study examined models that describe the factors involved in choosing an avatar and proposes a comprehensive model which includes a new factor. Suh, Kim, and Suh (2011) proposed a dualcongruity perspectives model: self-congruity (How does my avatar represent me?) and functional congruity (Does my avatar's appearance serve my purpose for using it: roll-playing, dating, etc.?). Martey and Consalvo (2011) added the importance of an online group perspective (Does my avatar's appearance fit my online group's norms?). This research proposes a quad-congruity perspectives model by adding a fourth factor to that conceptual framework: the constraining effect of offline culture and norms.

\section{Methodology}

This descriptive research employs both quantitative and qualitative tools: questionnaires, observations, and interviews. Looking at the differences between the avatars, we examined the ways students from different cultures chose and shaped their avatars' appearance to represent themselves. 
We looked for similarity between the user's appearance and his/her avatar - within a set of possible avatars in $S L$ - while examining the users' culture and norms in relation to the research questions.

\section{Research Questions}

1. Does the user's physical appearance affect his/her avatar's appearance? In particular, is there a similarity between the student's appearance in real life and his/her avatar's appearance?

2. Does the user's culture affect his/her choice of avatar? Does the virtual 3D environment blur multicultural differences?

3. Does the similarity between students and their avatars contribute to their learning experience?

\section{The Subjects}

Data was collected from the following sources:

1. 2011: 90 Israeli undergraduate students from six teacher training colleges: Arab (AlQasemi, The Academic Arab College), Jewish religious (Lifshitz, Talpiot) and Jewish secular (Kibbutzim, Levinsky) participated in a pilot study.

2. 2012: 63 Israeli undergraduate students from eight teacher training colleges: Arab (AlQasemi), Jewish religious (Lifshitz, Talpiot, Hemdat Hadarom), Jewish secular (Kibbutzim, Levinsky) and a multicultural college (David Yellin).

3. 2012: 26 Israeli graduate students from the Kibbutzim College (collaborating with Texas University students that were not part of the study).

4. 2013: 16 Israeli graduate students from the Kibbutzim College.

Most of the students were females $(80 \%)$. The ages of the undergraduate students ranged from 20 to 35 and of the graduate students from 36 to $50.60 \%$ of the students defined themselves as secular, $40 \%$ defined themselves as religious, $64 \%$ defined themselves as liberal and $36 \%$ defined themselves as conservative.

\section{Research Variables}

The dependent variable was the avatar's appearance (hair style, skin and hair color, height, dressing style and accessories, etc.)

The independent variables were the students' appearance (hair style, skin and hair color, weight, height), age, culture, nationality, religious tradition, gender, dress and fashion norms of the student and of his/her group.

\section{Instruments}

Three research tools were used:

1. A questionnaire was constructed by the researchers and was revised after the pilot. The questionnaire enabled the researchers to collect appearance data on students and their avatars and to answer the first research question by comparing the appearance data of students with that of their avatars. The answer to the first research question was compared with the students' culture to provide an answer to the second research question, and with the students' opinion regarding the contribution of similarity between students and their avatars to their learning experience in answer to the third research question. 
2. Interviews with some of the subjects $(\mathrm{N}=26)$ helped to clarify unclear data collected in the questionnaire (1) and these were compared with the analysis of the questionnaire for cross-checking. The interviews also helped to clarify and explain students' opinions regarding the contribution of similarity between them and their avatars to their learning experience and to explain the reason for this contribution - to answer the third research question.

3. Observations of photos and movies of avatars (qualitative) - like the interviews, the observations enabled cross-checking, to clarify and verify questionnaire data and to deepen the understanding of the research issues.

The qualitative tools enabled a deeper analysis of students' opinions regarding the research questions, verification of questionnaire data, and clarification of additional issues that emerged from analysis of the questionnaires.

\section{Procedure}

Undergraduate students $(\mathrm{N}=90)$ from different cultures participated in a pilot research (2011). They were divided into 20 themed groups of six members, each one from a different college and each two from a different culture (Hotter et al., 2009). Group members collaborated in writing a scenario on the group theme and presented it at a recorded meeting in a location in Second Life which they chose that suited the group theme. The pilot helped to rephrase criteria for analyzing the avatars, to eliminate data categories, and accordingly to revise and improve the questionnaire.

A similar group of undergraduate students $(\mathrm{N}=63)$ from different cultures (from eight colleges two from each culture: Arab, secular and religious Jewish, and two multicultural) participated in this research in 2012 using the improved research tools.

Another group of graduate students from the Kibbutzim College $(\mathrm{N}=42)$ who were involved in a similar project of collaborative learning in $S L$ with American graduate students from Texas University also participated in the research in 2012. They were divided into ten mixed groups of Israelis and Americans according to members' availability and were strangers to one another offline. They worked in $S L$ adjusting or reshaping their avatars. Group members collaborated to accomplish a task related to their group subject. The avatars' voice, dress, and movements were recorded and sent to the course site - see an example at http://www.youtube.com/watch?v=Tbl7m2gJ7zo\&feature=youtu.be

\section{Data Analysis}

Students who participated in the study answered a survey that included questionnaires and interviews. The questionnaires measured the appearance and dress of students and their avatars and the similarity of students to their avatar in these elements: cultural norms such as being conservative or liberal, their religion and religiousness, and their experience in SL. Questionnaires, field notes from session observations, interview transcripts, and session recordings were analyzed for categories of appearance, use of clothing and accessories, and individual identity cues. Quantitative data were analyzed using the following statistical tools: Cross Tabs, Pearson Chi-Square Tests, Symmetric Cramer's V Test, Means, and Spearman's Nonparametric Correlations.

The avatars were gathered from the forums in which the students presented their avatars. Although they could choose among dozens of virtual representations, the students chose only avatars with human figures. The main female figures chosen by the students are presented in Figure 1: 


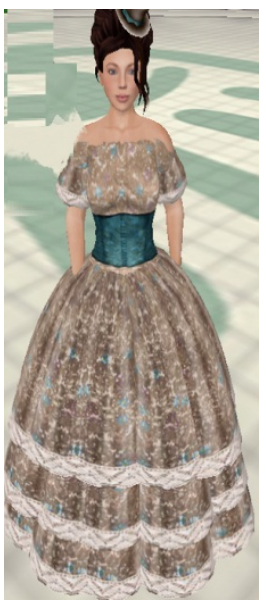

Avatar1

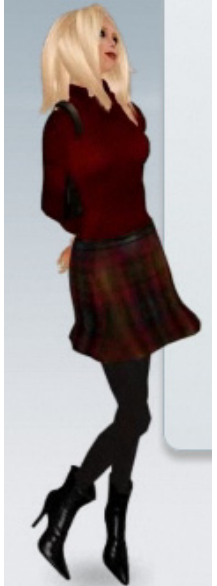

Avatar 2

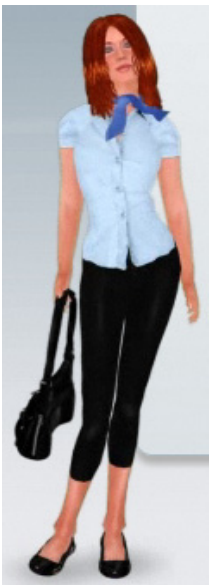

Avatar 3

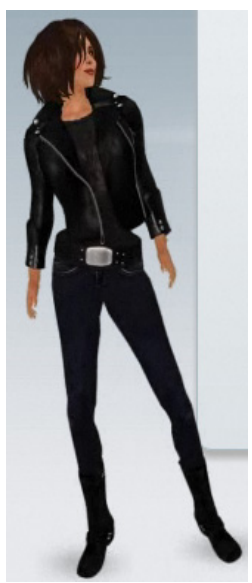

Avatar 4

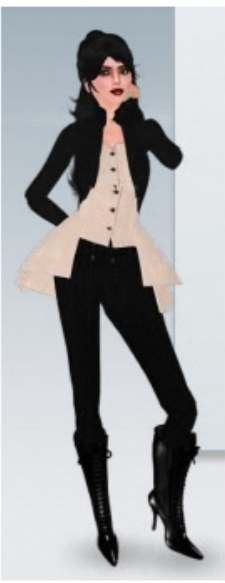

Avatar 5

Figure 1: Main female figures chosen by the students

Most undergraduate students used the basic figure afforded by Second Life, while graduate students formatted the figures. In the interviews, they explained that how the avatar looked was important to them because they related to their colleagues' avatars as if at a face-to-face meeting.

Several features of avatars were examined in comparison to the subjects' features: gender, skin color, clothing type (dress/trousers) and style (conservative/liberal), hair color, accessories, height, and weight. A Cramer correlation was calculated for each element of the avatar in comparison to those of the student. The results are presented in Table 1. The table shows that there is full correlation in terms of gender $(100 \%)$, indicating that there was no case of a female student who chose a male avatar or vice versa. There is also a high correlation in skin color, clothing type, hair color, and weight. The other features show significant but lower correlation.

Table 1: Correlation between avatars' features and students' features

\begin{tabular}{ll}
\hline Feature & Cramers' V \\
\hline Gender & $* * 1.00$ \\
Skin color & $* * 0.44$ \\
Clothing type (dress/trousers) & $* * 0.46$ \\
Clothing style (conservative/liberal) & $* 0.12$ \\
Hair color & $* * 0.51$ \\
Accessories & $* * 0.38$ \\
Height & $* * 0.39$ \\
Weight & $* * 0.64$ \\
\hline$* * \mathrm{p}<0.01, * \mathrm{p}<0.05$ &
\end{tabular}

Features were sorted into two groups:

1. Physical features that included gender, skin color, hair color, height, and weight

2. Cultural features that included clothing type (dress/trousers), style (conservative/liberal), and accessories. 
The correlation between the student and the avatar was calculated in the following way: When an avatar was identical to the student, it scored 1; if not, the score was 0 . Scores were grouped into three indices: physical correlation, cultural correlation, and general correlation. The scores were converted into percentages. The cultural correlation was found to be on a level of $75 \%$ or higher; physical correlation on a level of $80 \%$ or higher, and overall correlation of $67 \%$ or more.

Figure 2 shows a small distribution in the general correlation but the physical correlation shows a wider distribution and an even wider one in the cultural correlation.

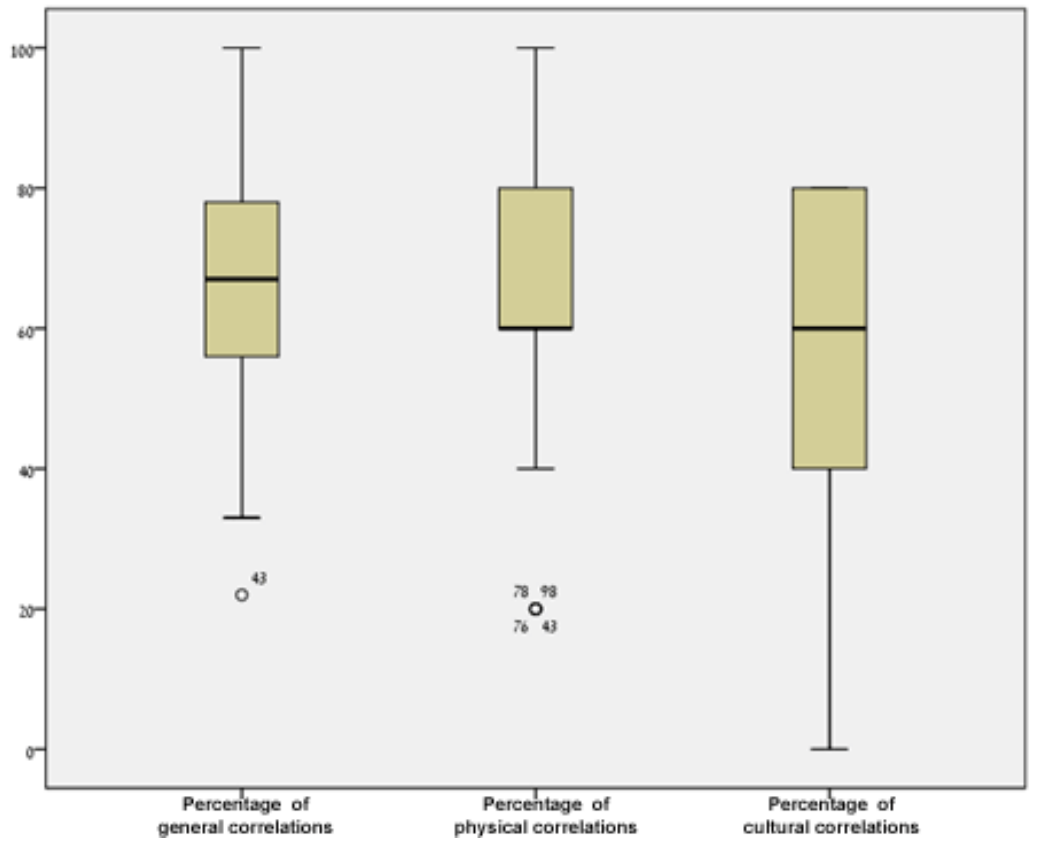

Figure 2 - Distribution of percentages of correlations

\section{Differences between groups}

Comparisons were made between the similarities of avatars to students in the different groups according to type of colleges (Jewish, Arabic, religious, and secular) and undergraduate or graduate students.

Table 2: Comparison between undergraduate and graduate students

\begin{tabular}{llllll}
\hline & Group & $\mathrm{N}$ & Average similarity & SD & $\mathrm{t}$ \\
\hline All & Undergraduate & 63 & 66.83 & 17.16 & $* 2.229$ \\
& Graduate & 42 & 78.45 & 16.67 & \\
\hline Physical & Undergraduate & 63 & 77.46 & 19.17 & 0.82 \\
& Graduate & 42 & 77.14 & 19.54 & \\
\hline Cultural & Undergraduate & 63 & 65.87 & 26.68 & $* * 2.724$ \\
& Graduate & 42 & 79.76 & 24.84 & \\
\hline
\end{tabular}

$* \mathrm{p}<0.05 \quad * * \mathrm{p}<0.01$


Table 2 presents the differences between undergraduate and graduates relating their similarity to their avatar in general and specifically in physical appearance and in cultural appearance. The Standard Deviation (SD) and the significance (t) are presented as well.

Significant differences were found between undergraduate and graduate students in the percentages of similarities to the avatar. A T-test for independent samples revealed a significant difference: graduate students formatted their avatars more similarly to themselves than did undergraduates. The table shows no differences between groups in physical similarity; however, there is a significant difference in cultural similarity and in general similarity. There were no gender or age differences.

\section{Cultural differences}

To examine cultural differences between students, an ANOVA test was performed to find differences between the avatars' clothing type (dress/trousers) and style (conservative/liberal) and groups, according to the type of college, students' beliefs (religious/secular) and self-image (liberal/conservative). The results are presented in Table 3.

Table 3: Correlation between clothing style and type of college

\begin{tabular}{|l|l|l|l|}
\hline \multirow{2}{*}{} & \multicolumn{2}{|l|}{$\begin{array}{l}\text { Clothing style } \\
\% \text { in type of college (N) }\end{array}$} & \multirow{2}{*}{ Total } \\
\cline { 2 - 3 } & Liberal & Conservative & \\
\hline Jewish religious & $41.7 \%(5)$ & $58.3 \%(7)$ & $100.0 \%(12)$ \\
\hline Arab & $40.0 \%(8)$ & $60.0 \%(12)$ & $100.0 \%(20)$ \\
\hline Multicultural (public) & $80.0 \%(24)$ & $20.0 \%(6)$ & $100.0 \%(30)$ \\
\hline Total & $59.7 \%(37)$ & $40.3 \%(25)$ & $100.0 \%(62)$ \\
\hline
\end{tabular}

A significant correlation was found $(\mathrm{p}<0.01)$ between the style of dress (conservative/liberal) and the attitudes of the students (conservative/liberal). Liberal students often chose avatars with a liberal clothing style while conservative students often chose avatars with conservative clothing styles (Cramer 0.3). In addition, a significant correlation was found between clothing style and degree of religiousness $(p<0.05)$. That is, religious students chose more avatars wearing dresses, while secular students chose avatars wearing trousers (Cramer 0.3). It is notable that among the religious students were religious Arabs who chose avatars wearing trousers but most of them with tunics (see Figure 1).

No difference was found in the style of the avatar's clothing (conservative/liberal) between religious and secular students. However, there was a significant difference $(p<0.01)$ between students in public colleges and religious ones (Arab and religious Jewish colleges). Students in public colleges chose avatars with liberal clothing styles while in religious institutions, there was a tendency to choose avatars dressed conservatively (Cramer 0.40).

The findings show that the look of the avatar is very relevant to students and affects them. Student A, a student from a religious college wrote:

"The Second Life project was interesting. I have to tell a story... The day we planned the meeting, I made my avatar, who was waiting in the island of the Kibbutzim college for five hours before the meeting. At 16:15 I went to the computer and when I entered the program I found my avatar naked. I did not know what to do... the guy was naked... at 
least I saw only his ... I looked for the clothing menu...I finally found a suit and left the hall, blushing..."

This is to emphasize that the representation of the student, the avatar, is not accidental but a true representation of the entity that is part of the student. Therefore, he feels discomfort when the avatar is naked or if it does not suit how he looks in real life.

\section{Contribution to the learning experience}

An important issue examined in this research is the extent of the contribution of learning through avatars using SL to the learning experience. This aspect was examined using three questions relating to the contribution of the avatar to the learning experience and to learning in groups when the avatar is similar to the student in its appearance. The three questions were found to be highly correlated (Cronbach's alpha 0.92). Thus, a scale "contribution to learning" was created representing the sum of the answers to the three questions and ranging from 0 to 3 . The average was 2.02 (SD 1.33) and more than half (66\%) of the students answered 3 on all three questions.

Differences between groups for the scale "contribution to learning" were examined. Contribution to learning for graduate students was found to be higher (2.21) than for undergraduate students (1.89). However, a T-test for independent samples revealed that the difference is not significant. No significance difference was found for groups of undergraduate students in relation to age, gender and experience in SL. However a significant difference was found in the different colleges (religious, public and Arab), as shown in Table 4:

Table 4: Contribution to learning according to college type

\begin{tabular}{llll}
\hline & $\mathrm{N}$ & Mean & $\mathrm{SD}$ \\
\hline Religious & 12 & 2.42 & 1.00 \\
Public & 31 & 1.39 & 1.43 \\
Arab & 20 & 2.35 & 1.14 \\
\hline Total & 63 & 1.89 & 1.35 \\
\hline
\end{tabular}

Table 4 shows that the contribution to learning among students from public colleges is lower than among students from religious and Arab colleges. One way ANOVA revealed a significant difference $F(2,60)=4.772$ when $p=0.012$. A post-hoc test revealed that the differences are significant between public colleges and both religious colleges $(\mathrm{p}=0.052)$ and Arab colleges $(\mathrm{p}=0.028)$.

\section{The Contribution of the Virtual Learning Environment}

Analysis of the students' reflections about the virtual learning environment suggests that the virtual environment brings people together, reduces gaps, and allows for communication with people one would never meet in traditional learning spaces.

G., a graduate student, explains, "It was an experience to develop my own avatar and ... get to know different people and communicate across the world."

P., a student from the US who is studying Hebrew, noted, "It allows the bridging of cultures and distances, using virtual platforms. For me, the most exciting part of the project was the opportunity to work with, and learn more about, the Israelis." 
The excitement of working with people from another culture around the world contributed to the learning experience. This reaction was found in all projects examined, including the inter-college learning projects of the TEC center, as W., a student from a religious college, explains, "Second Life is a virtual world within which you can be who you want, where you want and when you want - to be anyone at any time and anywhere. In the world we managed to work and create different videos, full of interest and energy of life and managed to communicate with each other when each one is in her home with her computer."

It seems that the option to change the avatar allows participants to experience success and to generate interesting products. Hence there is enthusiasm about learning in virtual environments based on avatars. This indicates that creativity, imagination, and reality-creation release students from barriers, as H., a student from a public college, stated, "Such teaching provides tools to use the student's imagination: to become what he dreams, to be in magical places. The opportunity to meet new people allows shy students to express themselves."

For B., a student at an Arab college, this was not only a learning experience but also implemented in teaching in school:

"The Second Life program was just perfect. I'm really thankful to you that you introduced us to this wonderful virtual reality program. As I mentioned in the English group forum and in our last face-to-face meeting, I applied what we learned about SL at the school where I practice teaching. It was just a great success. The pupils, with microphones and avatars visited two islands dedicated to teaching English, Virtlantis and Cypris, and attended and participated in two organized activities. I communicated with the creators of these islands and organized the activities with them."

However, there are negative responses as well; some due to specific subject matter that requires face to face meetings such as nature studies; for example, D. describes other difficulties, as well as advantages, "It seems that virtual worlds are still not intuitive and learning to use them takes time, so at first I was a bit confused but I managed in the end. The task itself and the idea were great, especially so that we can think about learning activities that our students can do in virtual worlds."

It seems that a significant portion of the students who built avatars and studied with them found that the process adds to the learning experience. They also enjoyed meeting avatars from other cultures in Israel and abroad and implemented the virtual learning environment in their teaching. Yet some students had difficulty using the environment and learning with their avatar and this affected their learning experience negatively.

\section{Discussion and Conclusions}

This research was conducted in teacher training colleges in Israel during courses that were given to graduate and undergraduate students. Students worked in groups made up of students of different cultures, in virtual learning environments. Students were asked to create educational tasks in virtual domains, on the assumption that these virtual domains have high learning potential (Campbell, 2009), and that virtual representations affect learning (Falloon, 2010; Hamilton \& Nowak, 2010; Resta \& Shonfeld, 2013). This research tried to enhance the models and proposals for virtual representations in three-dimensional domains and ascertain their importance to the learner.

It was found that students find the virtual representations which they chose important and that they connect them to the learning experience and to learning in groups. This importance was found in both graduate and undergraduate students and was found to be higher in religious Jewish and Arab students. It should be noted that there were students who shied away from virtual envi- 
ronments and from the use of avatars in learning. This is why it is important to introduce students to virtual teaching environments, which are becoming an integral part of our world (Campbell, 2009) and contribute not only to social presence, but also to the involvement of students and to interaction with others (Resta \& Shonfeld, 2013).

The students all chose and designed avatars that were similar to them. Students of all creeds, cultures, and religions found importance in the likeness of the virtual representations to themselves. It should be noted that graduate students created the avatars closest to their own image, perhaps because they are more experienced in virtual worlds. Thus, it could be important to implement virtual worlds in a friendly environment where students can easily change and shape their avatar. In this case, teachers as well as students will prefer to work in virtual worlds and immerse in the learning environment such as medieval history places, Shakespeare Theater, or Science Museum. Teachers are reluctant to virtual environments because it is not easy to build their avatar and control it.

Cultural differences were found to influence the appearance of the avatars; virtual environments do not distort cultural differences. Students who belong to a culture in which women wear dresses chose avatars wearing a dress; Arab students who wear conservative garb with trousers, chose avatars with trousers and a tunic top. In other words, the virtual representations preserved the outer differences of the culture. However, it was found that there was a difference in the importance given to the appearance of the avatar when comparing students from public secular colleges and students from Arab and Jewish religious colleges. Students from colleges characterized by specific cultural garb (Arab and Jewish religious) gave significantly higher value to the cultural characterization of the avatar. That is to say, students who came from a conservative culture wanted to preserve the conservative look in the virtual world. Thus, virtual worlds can replace the real meeting place and serve as a good platform for social educational events, such as conferences, workshop and for educational games.

As a result of these findings, this research suggests to broaden the dual-congruity model (Suh, Kim, \& Suh, 2011) and present the quad-congruity model. To self-congruity (How does my avatar represent me?) and functional congruity (Does my avatar's appearance serve my purpose for using it? role-playing, dating, etc.), Martey \& Consalvo (2011) added the importance of the online group perspective (Does my avatar's appearance fit my online group's norms?). This research proposes a quad-congruity perspectives model by adding a fourth factor to that conceptual framework - the constraining effect of offline culture and norms.

1. Self-congruity (similarity between students and their avatars). It was apparent that the students wanted the avatars that represent them to be in their likeness and represent them well, yet have an up-to-date appearance. We found a common high correlation between students and their avatars in all groups. These findings are compatible with the model presented by Suh, Kim, and Suh (2011) as to self-similarity.

2. Functional congruity. The avatar's function (for example, play acting, romantic acquaintanceships) influences the choices made as to what it looks like. These findings were ascertained by interviews with students in which they talked about changing the avatar's look for the benefit of the group task. Students who prepared a demonstration of a virtual classroom became pupils in their own likeness, and one of the members of the group "put on" the character of a teacher or a trainer. These findings correlate with the model of Suh, Kim, and Suh (2011) pertaining to the choice of different avatars in correlation with the role a student has within the group.

3. Group Identity congruity. As in reality, virtual environments are influenced by the cultures and norms of their members. In order to incorporate themselves and fit in well within the virtual group, its members will design the look of their virtual representations according to 
the norms of the look of the group and the environment in which the group operates. This component was found by Martey and Consalvo (2011). This research also found the look of the avatar important to the integration and learning of the members of the group.

4. Cultural congruity. This applies to the culture and norms of the participant. This factor is not characterized in the literature and is significant in this study. Religious Jewish students wore dresses and Arabs wore tunics while secular students wore trousers. Students from the Arab and religious Jewish colleges viewed the appearance of the avatar as more important than students in the public (secular) colleges. This may be a result of their being conservative and therefore feeling that their virtual representative must be conservative as well. This research revealed that culture and norms limit the design of the avatar.

3D dimensional environments enable learning that emulates face-to-face meetings while retaining the advantages of online learning. This offers new possibilities and promotes inter-college and international courses. An image chosen by a person as an avatar promotes stronger relational ties with others. Avatar choice is an important decision for those interested in becoming better connected in online environments. Creating an avatar not only helps students to interact with others, but as this research shows, it also contributes to their learning experience and online abilities by encouraging collaboration with group members, accomplishing tasks, and becoming part of the group.

Students emphasized the importance of the intercultural meeting, but prefer to maintain a sense of their cultural background while they were involved in new ways of learning and thinking. It seems that learning in virtual environments enables familiarity with students from different cultures who differ in appearance and speak different languages (Shonfeld \& Raz, 2012)

This study was performed on a limited group of students; it is advisable to examine other populations. Moreover, the results are based on students' opinions; therefore, we recommend further study based on continuous observation of learning activities in virtual environments to examine the contribution of the avatars to the learning experience. In addition, interviews with students who experienced learning in virtual worlds can deepen our understanding of learning in these environments, as well as contribute to development of such environments. This might promote the development of virtual environment use tailored to different populations such as young pupils, adolescents, and college students as well as students with special needs.

\section{References}

Abram, S. (2007). At Second Life, info pros will find much to see, do, learn, play with, try out. Information Outlook, 11(4), 34-36.

Avatar. (n.d.). In Merriam-Webster online dictionary. Retrieved from http://www.merriamwebster.com/dictionary/avatar

Bailenson, J. N., Swinth, K. R., \& Hoyt, C. L. (2005). The independent and interactive effects of embodied agent appearance and behavior on self-report, cognitive, and behavioral markers of copresence in immersive virtual environments. Presence: Teleoperators and Virtual Environments, 14, 379-393.

Barret, J. L. (1997). Anthropomorphism, intentional agents, and conceptualizing god. Unpublished doctoral dissertation, Cornell University, Ithaca.

Boulos, M. N. K., Hetherington, L., \& Wheeler, S. (2007). Second Life: An overview of the potential of 3D virtual worlds in medical and health education. Health Information \& Libraries Journal, 24, $233-$ 245.

Brahnam, S. (2009). Building character for artificial conversational agents: Ethos, ethics, believability, and credibility. PsychNology Journal, 7(1), 9-47. 
Breazeal, C. (2003). Emotion and sociable humanoid robots. International Journal of Human-Computer Studies, 59(1-2), 119-155.

Campbell, C. (2009). Learning in a different life: Pre-service education students using an online virtual world. Journal of Virtual Worlds Research 2(1).

Carmi, G. (2008). Lemida besviva metuksheret kemetayevet netiot hashiva intelektualiot[Learning in an communicated environment as enhancing of intellectual thinking attitude]. Unpublished doctoral thesis, Bar-Ilan University, Israel.

Carmi, G., \& Man, A. (2012). Sifriot Baolam Havirtuali "Second Life": Skirat Hitpathut ve Teur Peilut [Libraries at the virtual world "Second Life"]. Meidaat, 8, 17-32.

DiSalvo, C., \& Gemperle, F. (2003). From seduction to fulfillment: The use of anthropomorphic form in design. Paper presented at the 2003 International conference on designing pleasurable products and interfaces, Pittsburgh, PA, USA.

Falloon, G. (2010). Using avatars and virtual environments in learning: What do they have to offer?. British Journal of Educational Technology, 41(1), 108-122.

Galanxhi, H., \& Nah, F. F. (2007). Deception in cyberspace: A comparison of text-only vs. avatarsupported medium. International Journal of Human Computer Studies, 65(9), 770-783.

Garau, M., Slater, M., \& Vinayagamoorthy, V. (2003). The impact of avatar realism and eye gaze control on perceived quality of communication in a shared immersive virtual environment. Paper presented at the CHI'03 - The conference on human factors in computing systems, Fort Lauderdale, FL.

Hamilton, M. A., \& Nowak, K. L. (2010). Advancing a model of avatar evaluation and selection. PsychNology Journal, 8(1), $33-65$.

Hoter, E., Shonfeld, M., \& Ganayem, A. (2009). ICT in the service of multiculturalism. The International Review of Research in Open and Distance Learning, 10(2). Retrieved October 30, 2013, from http://www.irrodl.org/index.php/irrodl/article/view/601/1207

Jennings, N., \& Collins, C. (2007). Virtual or virtually U: Educational institutions in Second Life. International Journal of Social Sciences, 2, 180-186.

Kolko, B. E. (1999). Representing bodies in virtual space: The rhetoric of avatar design. The Information Society 15(3), 177-186.

Martey, R. M., \& Consalvo, M. (2011). Performing the looking-glass self: Avatar appearance and group identity in Second Life. Popular Communication, 9(3), 165-180.

Nass, C., \& Moon, Y. (2000). Machines and mindlessness: Social responses to computers. Journal of Social Issues, 56(1), 81.

Nowak, K. L., Hamilton, M. A., \& Hammond, C. C. (2009). The effect of image features on judgments of homophily, credibility, and intention to use as avatars in future interactions. Media Psychology, 12, 5076.

Nowak, K. L., \& Rauh, C. (2008). Examining the perception process of avatar anthropomorphism, credibility and androgyny in static and chat context. Computers in Human Behavior, 24(4), 1473-1493.

Peña, G., McGlone, M. S., \& Sanchez, J. (2012). The cowl makes the monk: How avatar appearance and role labels affect cognition in virtual worlds. Journal of Virtual Worlds Research 5(3).

Reeves, B., \& Nass, C. (1996). The media equation: How people treat computers, television, and new media like real people and places. Stanford, CA: CSLI Publications.

Resta, P. \& Shonfeld, M. (2013). A study of trans-national learning teams in a virtual world. In R. McBride \& M. Searson (Eds.), Proceedings of Society for Information Technology \& Teacher Education International Conference 2013 (pp. 2932-2940). Chesapeake, VA: AACE. Retrieved December 2, 2013 from http://www.editlib.org/p/48537 
Shonfeld, M., Hoter, E., \& Ganayem, N. A. (2013). Using ICT to bridge between cultures in conflict: The case of Israel. In R. S. P. Austin \& W. J. Hunter, W. J. Linking Schools: Online Learning and Community Cohesion. Ulstar Press.

Shonfeld, M., \& Raz, A. (2012). Using Second Life in the language classroom. In P. Resta (Ed.), Proceedings of Society for Information Technology \& Teacher Education International Conference 2012 (pp. 907-910). Chesapeake, VA: AACE.

Shonfeld, M., Resta, P., \& Yaniv, H. (2011). Engagement and social presence in a virtual worlds (Second Life) learning environment. In M. Koehler \& P. Mishra (Eds.), Proceedings of Society for Information Technology \& Teacher Education International Conference 2011 (pp. 740-745). Chesapeake, VA: AACE.

Suh, K., Kim, H. \& Suh, E. (2011). What if your avatar looks like you? Dual-congruity perspectives for avatar use. MIS Quarterly, 35(3), 711-729.

Taylor, T. L. (2002). Living digitally: Embodiment in virtual worlds. In R. Schroeder (Ed.), The social life of avatars, presence and interaction in shared virtual environments (pp. 40-62). London: SpringerVerlag.

Yee, N., \& Bailenson, J. N. (2007). The Proteus effect: The effect of transformed self-representation on behavior. Human Communication Research, 33, 271-290. 


\section{Appendix: The Survey Questionnaire}

1. Student's name

Group

College

Age

\section{Choose (circle) the right option for you and for your avatar:}

2. My gender:

Male Female

3. My avatar's gender:

Male Female

4. Experience in Second Life before the course:

None a little a lot

5. My skin color: White Dark

6. My avatar's skin color: White Dark

7. Religiousness - I consider myself as being: Religious Traditional secular

8. Values - I consider myself as being: Conservative Liberal

9. My clothing style is: conservative liberal sexy

10. My avatar's clothing style is: conservative (including conservative - sexy) liberal sexy

11. Usually I wear: dress (including skirt or long dress) pants (including tights or jeans)

12. My avatar wears: dress (including skirt or long dress) pants (including tights or jeans)

13. My hair color is: black blond red/brown

14. My avatar's hair color is: black blond red/brown

15. I wear requisites/ jewelry no yes

16. My avatar wears requisites/ jewelry no yes

17. Height - I am: short medium tall

18. Height - my avatar is: short medium tall

19. Weight - I am: slim medium fat

20. Weight - my avatar is: slim medium fat

21. Similarity - I think my avatar resembles me no yes

22. If I knew how to shape all aspects of my avatar's appearance, It would look more similar to me: No Yes

23. I was looking for avatar that: I like, and is different from me I like, and is similar to me just an avatar that I like

24. If I like my avatar and it is similar to me, it makes me feel more comfortable in my virtual group: No Yes

25. If I like my avatar and it is similar to me, it helps me assimilate in my virtual group and collaborate with other group members: No Yes

26. If I like my avatar and it is similar to me, it contributes to my learning experience: No Yes I don't know

\section{Thank you!}




\section{Biographies}

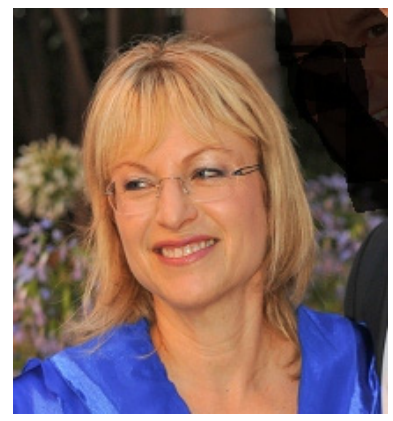

Dr. Miri Shonfeld is Head of The MOFET Institute's TEC Center and coordinator of the Master's degree in technology studies in education at Kibbutzim College of Education, Technology and the Arts. She is active in the fields of ICT, collaborative learning, and multicultural learning, in the organization of activities, in research, and in interest groups in Israel and abroad.

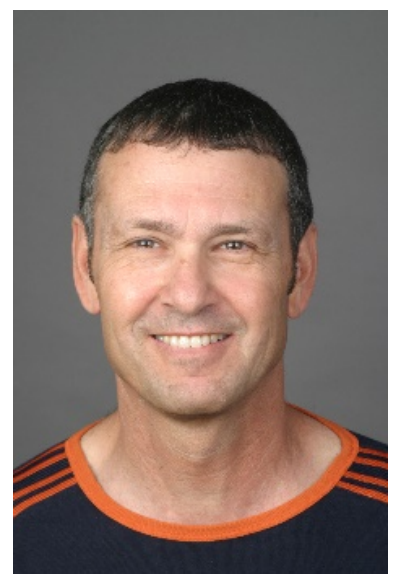

Dr. Miki Kritz is a senior lecturer at Kibbutzim College and an Academic-technological advisor in the field of ICT in teacher education. $\mathrm{He}$ is coordinator of the Online Environment Team at Mofet Institute and the Manager of the Amirim TEC Program at the TEC Center, where students from different cultures collaborate via the internet. $\mathrm{He}$ has published three books about the Internet and many articles about Progressive Education and online teaching environments. 